\title{
Revised Model of Abrasive Water Jet Cutting for Industrial Use
}

\author{
Libor M. Hlaváč $\mathbb{D}$
}

check for updates

Citation: Hlaváč, L.M. Revised Model of Abrasive Water Jet Cutting for Industrial Use. Materials 2021, 14, 4032. https://doi.org/10.3390/ma 14144032

Academic Editor: Pawel Pawlus

Received: 25 June 2021

Accepted: 16 July 2021

Published: 19 July 2021

Publisher's Note: MDPI stays neutral with regard to jurisdictional claims in published maps and institutional affiliations.

Copyright: (C) 2021 by the author. Licensee MDPI, Basel, Switzerland. This article is an open access article distributed under the terms and conditions of the Creative Commons Attribution (CC BY) license (https:// creativecommons.org/licenses/by/ $4.0 /)$.
Department of Physics, VSB-Technical University of Ostrava, 17. listopadu 15/2172, 70800 Ostrava, Czech Republic; libor.hlavac@vsb.cz; Tel.: +420-59-732-3102

\begin{abstract}
Research performed by the author in the last decade led him to a revision of his older analytical models used for a description and evaluation of abrasive water jet (AWJ) cutting. The review has shown that the power of 1.5 selected for the traverse speed thirty years ago was influenced by the precision of measuring devices. Therefore, the correlation of results calculated from a theoretical model with the results of experiments performed then led to an increasing of the traverse speed exponent above the value derived from the theoretical base. Contemporary measurements, with more precise devices, show that the power suitable for the traverse speed is essentially the same as the value derived in the theoretical description, i.e., it is equal to "one". Simultaneously, the replacement of the diameter of the water nozzle (orifice) by the focusing (abrasive) tube diameter in the respective equations has been discussed, because this factor is very important for the AWJ machining. Some applications of the revised model are presented and discussed, particularly the reduced forms for a quick recalculation of the changed conditions. The correlation seems to be very good for the results calculated from the present model and those determined from experiments. The improved model shows potential to be a significant tool for preparation of the control software with higher precision in determination of results and higher calculation speed.
\end{abstract}

Keywords: abrasive water jet; modelling; cutting; process control; industrial application

\section{Introduction}

The period of extensive use of water jet and abrasive water jet industrial application started more than 50 years ago. The first models for water jets were presented in the 1970s [1,2]. During the 1980s, Hashish presented his studies of abrasive water jets [3,4]. More recently, in the beginning of the 1990s, Hlaváč presented his theoretical model prepared for both water and abrasive water jets [5]. Later on, during the 1990s and in the beginning of the 21st century, many researchers all over the world continued modelling activities aimed at abrasive water jet machining. Regression-based models were prepared [6] and the first models for 3D machining were published $[7,8]$. Models aimed at including inherent phenomena have been prepared, namely, those describing processes in the mixing chamber and the focusing tube [9], in the interaction area [10,11] and some geometrical phenomena of the cutting processes. The research teams focused on processes with substantial impact on product geometry: origin of the cutting surface [12-14], formation of the striations [15-17] and the taper [18,19], determination of the jet lag inside kerf [20] and influence of the cutting parameters on the kerf geometry [21,22].

In recent years, many specific research applications have grown in importance. First of all, there are investigations aimed at some specific materials like thick metals [23] and titanium alloys for aerospace [24,25]. Some other interesting materials are glass [26] or composites [27]. Very interesting research was performed by Akkurt [28], who studied the front characteristics in applications of the AWJ on brass. Some recent investigations focused on a suppression of the negative impact of the trailback and the taper on the product quality [29], namely, in machining of composites [30,31]. Other researchers focus on various mathematical-numerical methods and their applications in AWJ processes. 
These methods are, namely, finite element methods (FEM) [32,33], smoothed particle hydrodynamics (SPH) [34] and computational fluid dynamics (CFD) [35].

The investigation of AWJ machining cannot be adequate without research of abrasive materials. Some researchers focused on investigations of the disintegration of abrasive particles in the mixing process [36], others searched for new types of abrasive materials [37], others studied the recycled ones [38,39] or try to apply ice particles [40], as the most environmentally friendly abrasive. Some special applications like using the AWJ for sculpturing [41], micro-piercing [42] or micro-machining [43] bring new challenges for researchers dealing with water jetting. However, the studies of applications of AWJ on the "classical" materials like tiles [44], wood [45] or Hardox [46] can also bring about new knowledge. The problem of surface quality is often closely tied in with the surface roughness. Therefore, many investigations were performed to assess, predict or monitor this parameter [47-50]. A few publications were also addressed at the reliability and safety problems of water jet technologies [51] or other related problems. However, preparation of the theoretical and more complex models is quite rare in the last decade. Therefore, partial models focused on either the mixing processes [52], modelling of the abrasive particles energy [53], or on the preparation of some superstructures for previous models [54,55], or in combination, have been presented. Recent research effort is focused on numerical modelling of abrasive water jets, e.g., the impact on material and the respective kerf shapes [56] or modelling of the micro-machining process imprint shapes [57]. However, the upgraded analytical model of the abrasive water jet that is presented in this article can be a new direction for the innovation of control systems for abrasive water jetting facilities and the development of some new devices, improved software systems, or in combination.

\section{Plain Waterjet-Material Interaction: Summary of the Initial Physical Model}

The model of water jet (WJ) interaction with material has been derived by applying the analytical physical description of the interaction process and it was presented in [58]. The derivation of this initial model was based on application of basic physical principles-the energy conservation law and the momentum conservation law. The resulting two equations are necessary for a development of the subsequent abrasive water jet model. Therefore, the most important forms presented in [58] are summarized here:

$$
\begin{gathered}
h_{n+1}=\frac{\pi d_{o} \sqrt{2 \rho_{o} \mu^{3} \gamma_{p}^{3} p_{o}^{3} e^{-5\left(\xi L+\xi^{*} h_{n}^{*}\right)}}\left(1-\alpha_{n}^{2}\right) \cos \theta}{8 \chi \rho_{M}{\widetilde{\rho_{0}}}_{P}^{\rho_{M}}}\left(\alpha_{n}^{2} e^{-2\left(\xi L+\xi^{*} h_{n}^{*}\right)} \mu \gamma_{p} p_{o}+\frac{\rho_{o}}{\rho_{M}} \sigma\right) \\
\alpha_{n}=1-\frac{C_{f}^{2} \sqrt{2 \mu^{3} \gamma_{p}^{3} p_{o}^{3}} \rho_{M}^{*} k^{*}}{8 \sqrt{\rho_{o}} \eta \sigma_{s} a e^{3\left(\xi L+\xi^{*} h_{n}^{*}\right)}} \\
h_{n}^{*}=h_{1}+h_{2}+h_{3}+\ldots+h_{n-1}+h_{n}
\end{gathered}
$$

The first equation describes the depths of penetration of the pure water jet into a material in the $(n+1)$-th pass along the same trace. The axis of the impinging jet is tilted from the perpendicular to the surface in the "plane of cut" for the angle $\theta$. The "plane of cut" is determined by the traverse speed vector and the jet axis. The second equation calculates the energy absorption coefficient $\alpha$ after the n-th pass of the jet along the same trace. The third equation summarizes the penetrations of the individual passes to the total depth of penetration. The equations have been used in the expression for one pass and without tilting for the basic preparation of the AWJ model through the principles of 
similarity. Therefore, the AWJ derivation starts from the application of these two equations for calculations of the pure water jet's impact on materials:

$$
\begin{gathered}
h=\frac{\pi d_{o} \sqrt{2 \rho_{o} \mu^{3} \gamma_{p}^{3} p_{o}^{3} e^{-5 \xi L}}\left(1-\alpha^{2}\right)}{8 \chi \rho_{M}{\widetilde{v_{P}}}_{P}^{\frac{\rho_{o}}{\rho_{M}}}\left(\alpha^{2} e^{-2 \xi L} \mu \gamma_{p} p_{o}+\frac{\rho_{o}}{\rho_{M}} \sigma\right)} \\
\alpha=1-\frac{C_{f}^{2} \sqrt{2 \mu^{3} \gamma_{p}^{3} p_{o}^{3}} \rho_{M}^{*} k^{*}}{8 \sqrt{\rho_{o}} \eta \sigma_{s} a e^{3 \zeta^{2} L}}
\end{gathered}
$$

However, several additional specific phenomena typical for AWJ must be introduced into the model to prepare fairly reliable equations, as is described in the next sections.

\section{Differentness in Description of the Abrasive Water Jet Regarding Pure Water Jet}

The most important difference between the AWJ and the pure water jet is the presence of solid-state abrasive particles inside the resulting jet (flow). This contribution is aimed at the injection AWJ, but some resulting formulas can be applied even for the slurry jets. Nevertheless, the process of abrasive mixing with the water jet, specific for the injection jets, needs deeper analysis, because, contrary to the slurry jets, abrasive particles undergo a substantial size change during the mixing process. The abrasive particle size change has been studied many times for various purposes in the past, e.g., as a tool for the intended disintegration of some minerals or coal $[59,60]$. These studies have shown a substantial reduction of the particle size in the mixing process. Therefore, the equation for calculation of the abrasive particle size change needs to be included into the system of equations applied in the control loop of the cutting system. It can be used in this form (see [59]):

$$
a_{n}=\frac{a_{o}}{1+\frac{C_{D} \pi d_{0}^{2} \mu_{0}^{2} p_{0}^{2} \gamma_{0}^{2}}{24 \rho E_{p} a_{0} c_{o} c}}
$$

The next specific parameters modifying efficiency of the AWJ are connected with the energy losses and the momentum changes inside the mixing chamber and the focusing tube. To define these phenomena more precisely, Hlaváč introduced four coefficients modifying velocity of the mixture [9]. The first one modifies velocity according to the suction capacity when the number of incoming particles exceeds the limit for the proper mixing and particles acceleration $\left(C_{1}\right)$ :

$$
C_{1}=\frac{\pi \rho_{a} v_{i} a_{o}^{3}}{3 d_{o} q_{a}} \text { For } \frac{3 q_{a}}{\pi \rho_{a} a_{o}^{3}} \leq \frac{v_{i}}{d_{o}} \Rightarrow C_{1}=1
$$

The second coefficient $\left(C_{2}\right)$ indicates smooth flow, as the number of disintegrated particles passing through the focusing tube cross-section is limited:

$$
C_{2}=\frac{d_{a}}{\sqrt{6} a_{n}} \text { For } d_{a}>\sqrt{6} a_{n} \Rightarrow C_{2}=1
$$

Modification of the velocity due to the friction inside the focusing tube with respect to the material of the tube indicates coefficient $C_{3}$ :

$$
C_{3}=\left(1-f l_{a}\right)
$$

The fourth coefficient $\left(C_{4}\right)$ modifies the mixture velocity according to the size relations in the system "orifice diameter-abrasive particle size-focusing tube diameter". Consid- 
ering the non-zero number of the original sized particles in the mixture and their smooth flowing through the system, the coefficient $C_{4}$ can be determined as:

$$
C_{4}=1-\frac{\left(a_{o}+a_{n}+d_{o}\right)^{2}}{d_{a}^{2}} \text { for } d_{a}>0
$$

Equations (7)-(10) are presented here for better understanding of the final model preparation. The equations determine the coefficients applied for calculation of the resulting mixture velocity from the momentum conservation law.

$$
v_{a}=C_{1} C_{2} C_{3} C_{4} v_{i} \frac{q_{w}}{q_{w}+q_{a}}
$$

It is evident that Equation (11) is similar to the one already presented in the beginning of the modelling attempts [61]. It is because it is derived in the same manner, from the momentum conservation law. The coefficient of momentum transfer efficiency $\eta$ used by Hashish in [61] is replaced here by the product of four coefficients being calculated or set by the logical mathematical operations according to the actual state of the cutting process variables and the mixing conditions.

\section{Model of the AWJ Transformed from the WJ Model}

The AWJ model prepared by a direct transformation from the pure water jet model is based on analogy presumption. It is supposed that by transforming the liquid density and pressure and using the appropriate quantities in Equations (4) and (5) it is possible to obtain the equation for the depth of the AWJ penetration into material [9]. The first step is to determine the density of the mixed flow (water with abrasive) - this is determined by Equation (12).

$$
\rho_{j}=\frac{4 \rho_{a}\left(q_{w}+q_{a}\right)}{\pi \rho_{a} v_{i} d_{o}^{2}+4 q_{a}}
$$

The next step is to determine the respective pressure of the mixed flow, i.e., liquid with the density determined using Equation (12). This pressure is calculated from Equation (13).

$$
p_{j}=\frac{1}{2} \rho_{j} v_{a}^{2}
$$

Once these most important quantities are determined, the subsequent substitution is applied in Equations (4) and (5): $\rho_{o} \rightarrow \rho_{j}, \mu \gamma_{p} p_{o} \rightarrow p_{j}, \xi \rightarrow \xi_{j}, \alpha \rightarrow \alpha_{e}$. Other variables, especially the material properties like the density, the grain size, the strength (both the compressive/tensile and the shear) remain identical for the AWJ as for the pure water jet. The only specific characteristic is the permeability (used in the case of the pure water jet), because it is necessary to select some appropriate property instead for the AWJ cutting, particularly for steels and other metals, carbons, carbides and other materials with low water absorption and penetration. The material hardness $K$ (or $H V$ ) was selected as the proper variable for the AWJ machining and the respective equations were transformed into the forms presented in Equations (14) and (15), see also the citation [14], or Equation (16), see [55]. The exponent used for the traverse speed (number 1.5 instead of the ratio of the jet and the cut material densities) has been determined from the regressions of a huge amount of experimental data obtained on many cut materials in the late 1980s and during the 1990s.

$$
\begin{gathered}
h_{l i m}=\frac{C_{A} S_{p} \pi d_{o} \sqrt{2 \rho_{j} p_{j}^{3} e^{-5 \xi_{j} L}}\left(1-\alpha_{e}^{2}\right)}{8\left(v_{P}+v_{P \min }\right)^{1.5}\left(\rho_{m} p_{j} \alpha_{e}^{2} e^{-2 \xi_{j} L}+\rho_{j} \sigma_{m}\right)} \\
\alpha_{e}=1-\frac{\sqrt{2 p_{j}^{3}} K t_{i}}{8 \sqrt{\rho_{j}} \sigma_{m} a_{m}}
\end{gathered}
$$




$$
v_{P l i m}=\left[\frac{C_{A} S_{P} \pi d_{0} \sqrt{2 \rho_{j} p_{j}^{3} e^{-5 \xi_{j} L}}\left(1-\alpha_{e}^{2}\right)}{8 H\left(\rho_{m} p_{j} \alpha_{e}^{2} e^{-2 \xi_{j} L}+\rho_{j} \sigma\right)}\right]^{\frac{2}{3}}-v_{P \text { min }}
$$

Nevertheless, problems with determination of the proper interaction time $t_{i}$ in the efficiency coefficient $\alpha_{e}$ during the real time calculations in new control software being prepared in the last few years lead to the repeated detailed analysis of the process. This analysis uncovered the very important detail. During preparation of the original model of the AWJ [9] the above-mentioned substitutions were input. Subsequently, the correlation between experimental data and results calculated from that theory led to the introduction of the power 1.5 for the traverse speed. All further works were influenced by these decisions. Nevertheless, the experiments used for correlation were influenced by lower efficiency of the system generating the AWJ accompanied by the low accuracy of the devices measuring the pressure inside the high-pressure part of the system. The results were also influenced by less information about the abrasive material and its disintegration during the mixing process. All analyses, performed in the last few years, show that exponent applied at the traverse speed (1.5) is too high and the proper exponent is much closer to the value resulting from the original theoretical physical derivations, i.e., to "one". Therefore, the exponent has been decreased from the value 1.5 to the value "one" (derived originally from the basic equations for the energy and the momentum conservation laws). Another possible substitution related to the change from pure water to the abrasive mixture, $d_{0} \rightarrow d_{a}$, needs to be largely discussed. Although it seems logical that the focusing tube diameter should be used instead of the nozzle/orifice diameter, this substitution needs to be evaluated from the physical point of view. Provided that the diameter of the nozzle represents the amount of energy delivered to the interaction area, it cannot be replaced by the focusing tube diameter, because this change does not increase the energy portion (better said it reduces it). Nevertheless, if the diameter of the nozzle represents the amount of destroyed material, it could be replaced by the focusing tube diameter. Therefore, the actual equations for calculation of the jet penetration limit into the material, Equation (17), or the traverse speed limit for cutting of the selected thickness of material, Equation (18), have the subsequent forms:

$$
\begin{aligned}
& h_{\text {lim }}=\frac{C_{A} S_{p} \pi d_{a} \sqrt{2 \rho_{j} p_{j}^{3} e^{-5 \xi_{j} L}}\left(1-\alpha_{e}^{2}\right)}{8\left(v_{P}+v_{P \min }\right)\left(\rho_{m} p_{j} \alpha_{e}^{2} e^{-2 \xi_{j} L}+\rho_{j} \sigma_{m}\right)} \\
& v_{\text {Plim }}=\frac{C_{A} S_{P} \pi d_{a} \sqrt{2 \rho_{j} p_{j}^{3} e^{-5 \xi_{j} L}}\left(1-\alpha_{e}^{2}\right)}{8 H\left(\rho_{m} p_{j} \alpha_{e}^{2} e^{-2 \xi_{j} L}+\rho_{j} \sigma\right)}-v_{P \min }
\end{aligned}
$$

Supplementary equation for calculation of the efficiency coefficient $\alpha_{e}$ from the cutting process parameters, the material properties and other factors remains unchanged, commonly expressible in this form:

$$
\alpha_{e}=1-\frac{\sqrt{2 p_{j}^{3}} K t_{i}}{8 \sqrt{\rho_{j}} a_{m} \sigma_{s}}
$$

Equation (17) or Equation (18), together with Equation (19) and, of course, with the preceding ones, (6)-(13), are directly applicable in practice, both for predictive or analytical calculations. They can be also used for a preparation of the operating and control software for machining systems with AWJ (as was proved in the past with their older forms). Calculation of the coefficient $\alpha_{e}$ is much more convenient in practice from evaluation of the experimental cut made in material, especially when machining of materials with 
the untrustworthy material information. The appropriate relation for calculation of the coefficient $\alpha_{e}$ is then expressed as Equation (20):

$$
\alpha_{e}=\sqrt{\frac{C_{A} S_{p} \pi d_{a} \sqrt{2 \rho_{j} p_{j}^{3} e^{-5 \xi_{j} L}}-8 h\left(v_{P}+v_{P \min }\right) \rho_{j} \sigma_{m}}{C_{A} S_{p} \pi d_{a} \sqrt{2 \rho_{j} p_{j}^{3} e^{-5 \xi_{j} L}}+8 h\left(v_{P}+v_{P \min }\right) \rho_{m} p_{j} e^{-2 \xi_{j} L}}}
$$

In the case of machining processes other than cutting, additional equations may be necessary, describing some specific factors and the specific behavior of the jet in the respective processes. It is also important to add some equations describing the compensation of the jet delay and the taper during the cutting process $[19,55]$. The modification of the traverse speed, for meeting the requirements of a certain surface quality, can be calculated from Equation (21), introduced, e.g., in [55] and completed by $C_{Q}$ relation to the cut material behavior and the AWJ abrasive material type; the condition $C_{Q} \in(0 ; 1\rangle$ needs to be fulfilled, because the traverse speed needs to fulfil condition $v_{P} \in\left(0 ; v_{P \min }\right\rangle$.

$$
v_{P Q}=C_{Q} v_{P l i m}
$$

Similarly, an analogous equation can be derived for a determination of the depth in material with a selected quality of the side walls securable at the set traverse speed. However, the proper relation between the wall quality parameters and the respective traverse speed and other machining parameters needs further investigation for each material and its thickness. The values $h_{\text {lim }}$ or $v_{\text {Plim }}$ are determined from the actual $v_{P}$ and $h$ applying Equation (22) or Equation (23).

$$
\begin{gathered}
h_{\text {lim }}=h\left(\frac{\vartheta_{\text {lim }}}{\vartheta}\right)^{\frac{2}{3}} \\
v_{\text {Plim }}=v_{P}\left(\frac{\vartheta_{\text {lim }}}{\vartheta}\right)^{\frac{2}{3}}
\end{gathered}
$$

Respective declination angles determining the cutting wall quality are calculated from Equation (24) or Equation (25) within the scope of the jet energy proportionate to the material thickness.

$$
\begin{aligned}
& \vartheta=\vartheta_{\text {lim }}\left(\frac{h}{h_{\text {lim }}}\right)^{1.5} \\
& \vartheta=\vartheta_{\text {lim }}\left(\frac{v_{P}}{v_{\text {lim }}}\right)^{1.5}
\end{aligned}
$$

The usual angle limit for materials with the thickness correlating with the jet energy has a value of $45^{\circ}$, because both the cutting and the deformation wear of material are present during the jet-material interaction. However, if the material thickness exceeds the jet energy capacity, the deformation removal of material (the deformation wear) is impossible. The jet reflects from the kerf bottom in such a case. Therefore, the angle limit corresponds to the maximum angle for the cutting mode, i.e., approximately $22.5^{\circ}$. Very thick material pieces can also be cut, but it is necessary to set the traverse speed so low that the uncertainties in the cutting conditions (pressure, abrasive mass flow rate, material properties local change) cannot induce conditions for deformation wear (then the jet immediately starts to reflect from the kerf). Therefore, the declination angle limit further decreases to only $15^{\circ}$ or less. This limitation needs to be taken into consideration and it can depend on the material brittleness, hardness, toughness and strength [54]. The angle limit value can even decrease to $10^{\circ}$ for the most wear resistant materials cut by the standard abrasive materials (garnet, olivine). More intense studies of this problem are proceeding now and will be presented in future. The usual results for equipment and settings used in the Laboratory of Liquid Jet at the VSB-Technical University of Ostrava (see next sections) can be summarized in this way: the thickness limit for the declination angle $45^{\circ}$ is about 
$30 \mathrm{~mm}$, for the angle $22.5^{\circ}$ it is $60 \mathrm{~mm}$ and for the angle $15^{\circ}$ it is approximately $120 \mathrm{~mm}$. Over the thickness of $120 \mathrm{~mm}$ it is necessary to use traverse speed producing the declination angle below $10^{\circ}$, otherwise the cutting process is disrupted and the jet rebounds from the kerf bottom.

The model was used for determination of the product deformation presented, namely, in [55] and the influence of the taper presented in [19]. The diameter of the cylindrical sample can then be calculated from this equation:

$$
D=2\left[\sqrt{\left(\frac{2}{5} H \tan \vartheta\right)^{2}+R^{2}}+\frac{2}{5} H \tan \varphi\right]-d_{a}
$$

The main benefit of the presented theoretical base is quite simple and relatively precise transformation of knowledge from the known and proven stages into new ones. Such transformations were presented during precision investigations in [62-64]. One of the most important is the transformation of the traverse speed limit for the different pressure and the abrasive mass flow rate. The subsequent equation can be used for this operation:

$$
v_{\operatorname{Plim} 2}=\frac{\sqrt{\rho_{j 2} p_{o 2}^{3}}}{\sqrt{\rho_{j 1} p_{o 1}^{3}}} v_{\operatorname{Plim} 1}
$$

Calculations of the traverse speed limits for the different jet parameters are very useful for comparison of results among workplaces with different experimental (manufacturing) facilities.

\section{Simplification of the Model for Implementation to the Control Systems}

In spite of the fact that the above presented model is derived by applying physical and mathematical procedures describing the objective phenomena and processes, its application in practice may appear too complicated and demanding. Therefore, the reduced form for rapid application is presented in this part of the article. The simplification is based on the fact that a very limited number of all the parameters, factors and characteristics influencing the machining process are actually changed in the AWJ applications in practice.

First of all, the important statement needs to be noted. The operation parameters like the nozzle/orifice diameter, the mixing chamber configuration, the focusing tube diameter, used liquid (predominantly water), used abrasive including its sizing as well as the operating pressure and the stand-off distance are very often constant for any applications in the given workplace in practice. Therefore, the simplified forms of the equations can be prepared by implementing the preset parameters in their numerical expressions. The very often used combination of these parameters in our laboratory/workplace is presented here as an example:

$\begin{array}{ll}\text { Operating pressure } & 380 \mathrm{MPa} \\ \text { Stand-off distance } & 2 \mathrm{~mm} \\ \text { Nozzle (orifice) diameter } & 0.25 \mathrm{~mm} \\ \text { Focusing tube diameter } & 1.02 \mathrm{~mm} \\ \text { Focusing tube length } & 76.2 \mathrm{~mm} \\ \text { Used liquid } & \text { water } \\ \text { Used abrasive } & \text { Australian garnet } \\ \text { Abrasive sizing } & 80 \text { mesh }(0.25 \mathrm{~mm}) \\ \text { Abrasive mass flow rate } & 0.25 \mathrm{~kg} \cdot \mathrm{min}^{-1} \\ \text { *Comment: Average grain size of Australian garnet } 80 \text { mesh has been measured in laboratories at the } \\ \text { VSB-Technical University of Ostrava several times on different measuring devices for particle size } \\ \text { anal-yses. The average value 0.25 mm has been determined and, therefore, it is used now in our } \\ \text { calculations, although some conversion tables present lower values (often below } 0.2 \text { mm). }\end{array}$


Using these data and the usual geometry of the water nozzle, the mixing chamber and the focusing tube (Paser II), the subsequent fixed values, summarized in Table 1, can be determined (e.g., in Excel).

Table 1. Variables determined for the tested configuration of the injection abrasive water jet.

\begin{tabular}{cccccccccc}
\hline Variable & Value & Unit & Variable & Value & Unit & Variable & Value & Unit \\
\hline$\mu_{0}$ & 0.5981 & - & $C_{A}$ & 0.0033 & - & $c_{o}$ & 1484 & $\mathrm{~m} \cdot \mathrm{s}^{-1}$ \\
$\gamma_{0}$ & 0.8993 & - & $S_{P}$ & 1.0000 & - & $c$ & 4600 & $\mathrm{~m} \cdot \mathrm{s}^{-1}$ \\
$C_{D}$ & 0.2000 & - & $f$ & 0.1000 & - & $v_{o}$ & 640 & $\mathrm{~m} \cdot \mathrm{s}^{-1}$ \\
$C_{1}$ & 0.7926 & - & $l_{a}$ & 0.0762 & $\mathrm{~m}$ & $v_{a}$ & 378 & $\mathrm{~m} \cdot \mathrm{s}^{-1}$ \\
$C_{2}$ & 1.0000 & - & $a_{O}$ & 0.2500 & $\mathrm{~mm}$ & $\rho_{j}$ & 1095 & $\mathrm{~kg} \cdot \mathrm{m}^{-2}$ \\
$C_{3}$ & 0.9238 & - & $a_{n}$ & 24.951 & $\mu \mathrm{m}$ & $p_{j}$ & 78.19 & $\mathrm{MPa}$ \\
$C_{4}$ & 0.9136 & - & $E_{P}$ & 2.8350 & $\mathrm{~J} \cdot \mathrm{m}^{-2}$ & $\xi_{j}$ & 1.142 & $\mathrm{~m}^{-1}$ \\
\hline
\end{tabular}

Examples of calculation of both the depth limit of penetration and the traverse speed limit are presented for selected metal materials (high strength steel, tool steel, stainless steel, very abrasive resistant Hardox 500 steel, copper, brass and duralumin) and rock materials (hard sandstone, limestone, marble, granite and strong granite). Mild sandstone was not used for these experiments, because it is so easily disintegrated that it can be cut very efficiently even by an almost pure water jet. Respective material characteristics are summarized in Tables 2 and 3.

Table 2. Parameters of metals; all samples were $10 \mathrm{~mm}$ thick.

\begin{tabular}{ccccc}
\hline $\begin{array}{c}\text { Material } \\
\text { (WRN/DIN Norm) }\end{array}$ & $\begin{array}{c}\text { Yield } \\
\text { Strength MPa }\end{array}$ & $\begin{array}{c}\text { Density } \\
\mathbf{k g} \cdot \mathbf{m}^{-3}\end{array}$ & $\begin{array}{c}\text { Response to AWJ } \\
\text { for the Water } \\
\text { Nozzle Diameter }\end{array}$ & $\begin{array}{c}\text { Response to AWJ } \\
\text { for the Focusing } \\
\text { Tube Diameter }\end{array}$ \\
\hline $\begin{array}{c}\text { High strength steel } \\
(1.7131 / 16 \text { MnCr 5) } \\
\text { Tool steel }\end{array}$ & 880 & 7746 & 120 & 39 \\
$\begin{array}{c}(1.2436 / \text { X210 CrW 12) } \\
\text { Stainless steel }\end{array}$ & 656 & 7674 & 108 & 36 \\
$\begin{array}{c}(1.4541 / \text { X6 CrNiTi 18 10) } \\
\text { Hardox 500 }\end{array}$ & 515 & 7521 & 100 & 34 \\
trademark of the SSAB \\
$\begin{array}{c}\text { Copper } \\
(2.0060 / \mathrm{E}-\mathrm{Cu} 57) \\
\text { Brass }\end{array}$ & 1679 & 7524 & 171 & 29 \\
$\begin{array}{c}(2.0402 / \text { CuZn40Pb2) } \\
\text { Duralumin }\end{array}$ & 393 & 8687 & 67 & 30 \\
$(3.1325 /$ AlCu4MgSi $)$ & 419 & 2784 & 73 & 15 \\
\hline
\end{tabular}

Table 3. Parameters of rocks; all samples were $30 \mathrm{~mm}$ thick.

\begin{tabular}{cccccc}
\hline Material & $\begin{array}{c}\text { Compressive } \\
\text { Strength } \\
\mathbf{M P a}\end{array}$ & $\begin{array}{c}\text { Grain Size } \\
\boldsymbol{\mu m}\end{array}$ & $\begin{array}{c}\text { Density } \\
\mathbf{k g} \cdot \mathbf{m}^{-\mathbf{3}}\end{array}$ & $\begin{array}{c}\text { Response to AWJ } \\
\text { for the Nozzle } \\
\text { Diameter }\end{array}$ & $\begin{array}{c}\text { Response to AWJ } \\
\text { for the Focusing } \\
\text { Tube Diameter }\end{array}$ \\
\hline Sandstone & 150 & 0.52 & 2590 & 183 & 80 \\
Limestone & 85 & 0.51 & 2420 & 156 & 70 \\
Marble & 100 & 0.52 & 2650 & 165 & 75 \\
Granite & 188 & 0.69 & 2557 & 201 & 83 \\
Strong granite & 291 & 0.40 & 3041 & 376 & 129 \\
\hline
\end{tabular}

As can be seen, the higher the value of the "response" to the AWJ the more difficult the cutting. However, it is also evident that the "response" factor is also dependent on the thickness of material used for the testing cut. Therefore, such a modification of 
the theoretical model was sought, which will allow excluding of the influence of the absolute size of the "response" of the AWJ. Recent results show that it is not necessary to apply the whole presented theoretical model. It can be accepted as the proven theoretical background and the practical applications can be based on the most recent knowledge expressed through Equations (21)-(25) and (27) or others derived on the base of similarity. Demonstration of this proposition is a content of the subsequent section.

\section{Comparison of Model Results with Experiments and Discussion}

Experimental works were performed in the Laboratory of Liquid Jet at the VSBTechnical University of Ostrava. The equipment consisted of the commercial x-y table with manually handled z-axis PTV WJ 1020-1Z-EKO (PTV s.r.o., Hostivice, Czech Republic) and the Flow X5 pump (Flow Int., Seattle, WA, USA). Special research devices for studying of the tilted jets and turning were added over the years. However, none of them allows a controlled change of the jet impact angle on the material and stand-off distance from the material. The pump maximum flow rate of $1.9 \mathrm{~L} / \mathrm{min}$ does not allow using orifices with diameters greater than $0.25 \mathrm{~mm}$.

Practical applications can be demonstrated in two main ways. The first one is based on a comparison of the measured sample deformation (caused by the trailback and the taper) with the calculated one. This comparison was presented in publications aimed at the deformation of samples prepared by AWJ machining, namely, [63,64]. Some new results demonstrating the calculation results are summarized in Table 4. Tilting is just compensating of the trailback, because the experimental equipment in the Laboratory of Liquid Jet at the VSB-Technical University of Ostrava is prepared for cutting of column samples, this enables tilting in only the tangential plane to the cylindrical sample shell, not in the radial direction. However, it can be assumed that the influence of the trailback is compensated for, and, therefore, the input diameter $D_{i t}$ is equal to the output one without influence of the "taper". The total theoretical diameter is then the sum of the theoretical input diameter $D_{i t}$ and the difference caused by the "taper" $T$ (both these values were calculated from the theoretical model summarizing the deformation of the sampleEquation (26)). Because the combined uncertainty of the sample measurements is $1.6 \%$, it is evident that the deviation of the respective experimental and theoretical values lies in this interval.

Table 4. Comparison of the theoretical calculations and the respective experimental data for the tilted cutting head.

\begin{tabular}{cccccccc}
\hline Material & $\begin{array}{c}\boldsymbol{v}_{\boldsymbol{P t i l t}} \\
\mathbf{m m} / \mathbf{m i n}\end{array}$ & $\begin{array}{c}\boldsymbol{D}_{\boldsymbol{i e}} \\
\mathbf{m m}\end{array}$ & $\begin{array}{c}\boldsymbol{D}_{\boldsymbol{o e}} \\
\mathbf{m m}\end{array}$ & $\begin{array}{c}\boldsymbol{D}_{\boldsymbol{i t}} \\
\mathbf{m m}\end{array}$ & $\begin{array}{c}\boldsymbol{T} \\
\mathbf{m m}\end{array}$ & $\begin{array}{c}\boldsymbol{D}_{\boldsymbol{o t}} \\
\mathbf{m m}\end{array}$ & $\begin{array}{c}\text { Relative } \\
\text { Difference } \boldsymbol{D}_{\boldsymbol{i}} ; \boldsymbol{D}_{\boldsymbol{o}}\end{array}$ \\
\hline High strength steel & 128 & 9.33 & 9.72 & 9.29 & 0.36 & 9.65 & $0.43 \% ; 0.72 \%$ \\
Tool steel & 93 & 9.34 & 9.66 & 9.31 & 0.36 & 9.67 & $0.32 \% ; 0.10 \%$ \\
Stainless steel & 116 & 9.32 & 9.63 & 9.28 & 0.37 & 9.65 & $0.43 \% ; 0.21 \%$ \\
Hardox 500 & 105 & 9.32 & 9.62 & 9.33 & 0.35 & 9.68 & $0.11 \% ; 0.62 \%$ \\
Copper & 221 & 9.30 & 9.72 & 9.29 & 0.37 & 9.66 & $0.11 \% ; 0.62 \%$ \\
Brass & 219 & 9.31 & 9.71 & 9.30 & 0.36 & 9.66 & $0.11 \% ; 0.52 \%$ \\
Duralumin & 443 & 9.30 & 9.69 & 9.28 & 0.37 & 9.65 & $0.22 \% ; 0.41 \%$ \\
\hline
\end{tabular}

The second demonstration is based on the comparison presented in Table 5. The respective experiments were performed with the AWJ facility installed in the Laboratory of Liquid Jet at the VSB-Technical University of Ostrava. 
Table 5. Comparison of the theoretical calculations and the respective experimental data.

\begin{tabular}{cccccc}
\hline Material & $\begin{array}{c}\boldsymbol{v}_{\text {PlimB }} \\
\mathbf{m m} / \mathbf{m i n}\end{array}$ & $\begin{array}{c}\boldsymbol{v}_{\text {Plim }} \\
\mathbf{m m} / \mathbf{m i n}\end{array}$ & $\begin{array}{c}\text { Theoretical } \\
\text { Angle } \mathbf{(}^{\circ}\end{array}$ & $\begin{array}{c}\text { Experimental } \\
\text { Angle }\end{array}$ & $\begin{array}{c}\text { Relative } \\
\text { Difference }\end{array}$ \\
\hline High strength steel & 220 & 262 & 10.60 & $10.55 \pm 0.37$ & $0.5 \%$ \\
Tool steel & 160 & 191 & 17.10 & $16.86 \pm 0.54$ & $1.4 \%$ \\
Stainless steel & 200 & 238 & 12.23 & $12.36 \pm 0.25$ & $1.0 \%$ \\
Hardox 500 & 180 & 214 & 14.33 & $14.37 \pm 0.15$ & $0.3 \%$ \\
Copper & 380 & 453 & 13.21 & $13.37 \pm 0.17$ & $1.2 \%$ \\
Brass & 376 & 448 & 13.42 & $13.20 \pm 0.03$ & $1.7 \%$ \\
Duralumin & 760 & 906 & 13.21 & $13.58 \pm 0.11$ & $2.7 \%$ \\
\hline
\end{tabular}

All presented calculations are based on transformations of the traverse speed limits from the proven measured ones into the new states determined for the different conditions only through calculations from the presented model. The basic traverse speed limit $v_{\text {PlimB }}$ is determined for the settings presented in the beginning of Section 5 (the classical settings). The samples demonstrating the strength of the theoretical model were cut with just one change in these settings: instead of the focusing tube with diameter $d_{a}=1.02 \mathrm{~mm}$ the one with diameter $d_{a C}=0.76 \mathrm{~mm}$ was used. The changed traverse speed limit $v_{P l i m N}$ was then determined. The new traverse speed limit was calculated from this equation, prepared from the theoretical model:

$$
v_{\operatorname{PlimN}}=v_{P \operatorname{PlimB}} \frac{d_{a}}{d_{a C}} \frac{a_{n C}}{a_{n}},
$$

where $v_{\text {PlimB }}$ is the traverse speed limit for the basic set of experimental conditions and $v_{P l i m N}$ is the traverse speed limit after changing the focusing tube; $d_{a}$ and $d_{a C}$ are the respective diameters of the original and the changed focusing tubes; $a_{n}$ and $a_{n c}$ are the medium sizes of abrasive particles after mixing process for the original and the changed focusing tubes, respectively (data based on the studies published in $[36,65]-a_{n}=24.95 \mu \mathrm{m}$, $\left.a_{n \mathrm{C}}=22.15 \mu \mathrm{m}\right)$.

Examples of the mean declination angles are presented on the photos of the experimental samples in Figures 1 and 2. These selected metal samples are ones from the series of three cuts performed under identical conditions. Respective values measured for all three samples of selected metals are summarized in Table 6.
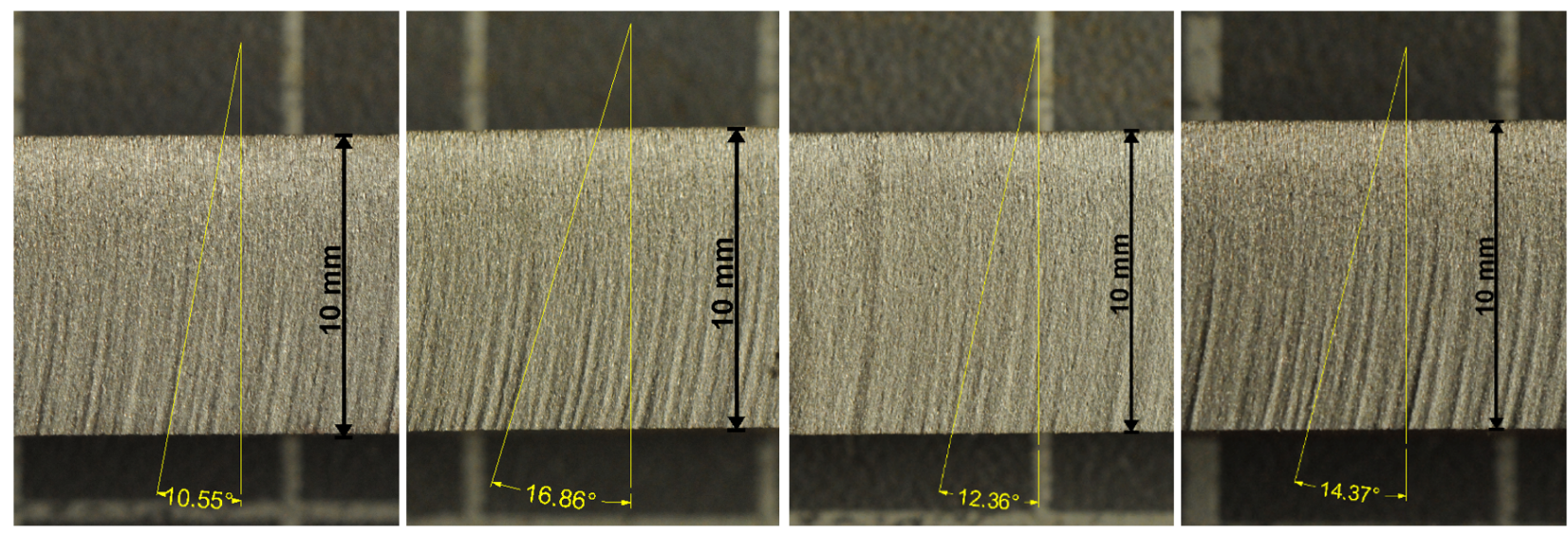

Figure 1. Steels and the respective average angles—-the order from the left to the right (WRN norm): high strength steel (1.7131), tool steel (1.2436), stainless steel (1.4541), Hardox 500 (trademark of the SSAB). 

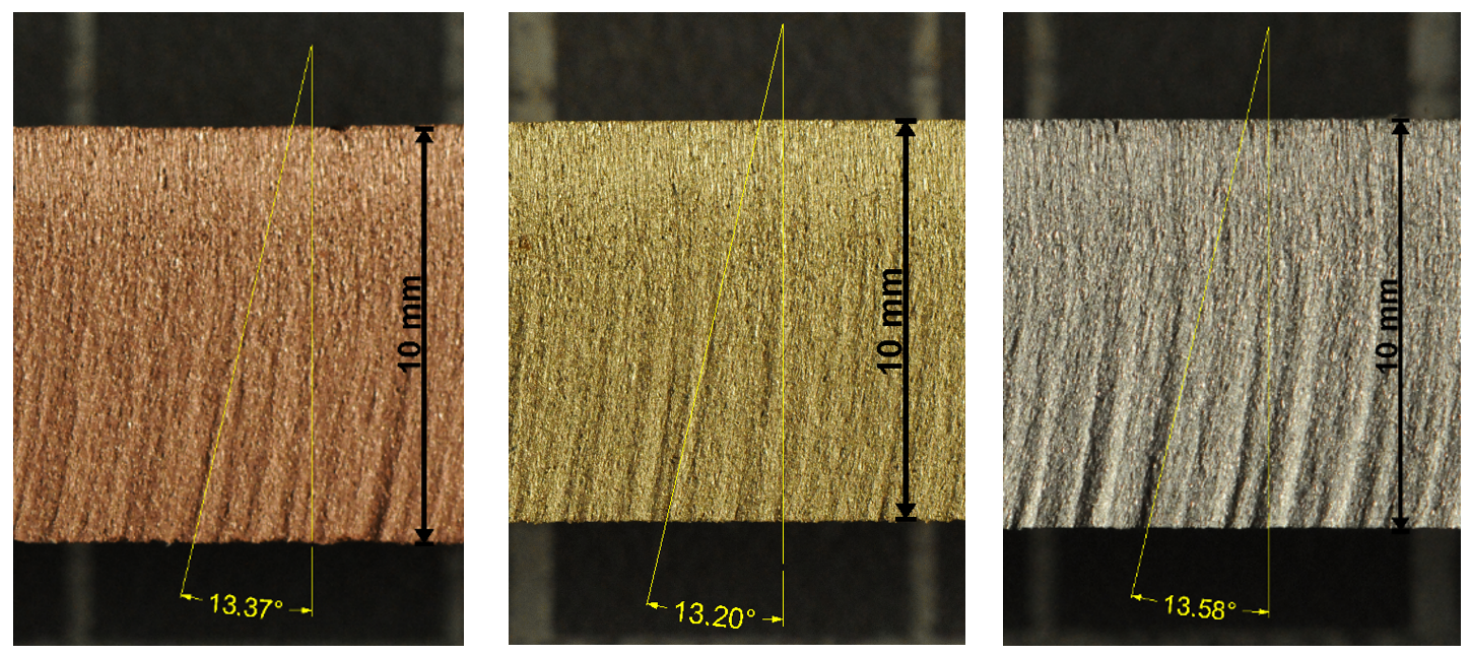

Figure 2. Non-ferrous metals and the respective average angles—-the order from the left to the right (WRN norm): copper (2.0060), brass (2.0402), duralumin (3.1325).

Table 6. The declination angles measured for experimental samples in degrees (10 measurements for each case).

\begin{tabular}{|c|c|c|c|c|c|c|}
\hline Material & $\begin{array}{c}\text { Experiment } \\
\text { I. }\end{array}$ & $\begin{array}{c}\text { Experiment } \\
\text { II. }\end{array}$ & $\begin{array}{l}\text { Experiment } \\
\text { III. }\end{array}$ & $\begin{array}{l}\text { Average } \\
\text { Value }\end{array}$ & $\begin{array}{l}\text { Absolute } \\
\text { Uncertainty }\end{array}$ & $\begin{array}{c}\text { Relative } \\
\text { Uncertainty }\end{array}$ \\
\hline High strength steel & 10.62 & 10.97 & 10.06 & 10.55 & \pm 0.37 & $3.6 \%$ \\
\hline Tool steel & 16.86 & 16.20 & 17.53 & 16.86 & \pm 0.54 & $3.2 \%$ \\
\hline Stainless steel & 12.25 & 12.12 & 12.71 & 12.36 & \pm 0.25 & $2.0 \%$ \\
\hline Hardox 500 & 14.22 & 14.32 & 14.59 & 14.37 & \pm 0.15 & $1.1 \%$ \\
\hline Copper & 13.32 & 13.60 & 13.18 & 13.37 & \pm 0.17 & $1.3 \%$ \\
\hline Brass & 13.21 & 13.22 & 13.16 & 13.20 & \pm 0.03 & $0.2 \%$ \\
\hline Duralumin & 13.46 & 13.60 & 13.56 & 13.58 & \pm 0.11 & $0.8 \%$ \\
\hline
\end{tabular}

It can be seen that both the relative difference between the theoretical and the experimental values is below $5 \%$ (Table 5 ) and the relative uncertainty of measurement on respective samples is also below $5 \%$ (Table 6). Therefore, the agreement of the theoretical and the respective experimental results can be considered as very good.

The presented model of the material cutting by AWJ is highly applicable on homogeneous and quasi-homogeneous materials-metals, rocks, concretes (if not reinforced or containing materials with extremely different mechanical properties), ceramics, glass and homogeneous plastics. The model needs additional "modification" for reinforced, sandwich, honeycomb or other non-homogeneous structures; it is applicable for these structures when they are well described and both the position and influence of the inhomogeneity is very predictable. The appropriate changes of the jet size when moving from one material to another need to be calculated and the respective power loss needs to be evaluated and taken into account.

The presented results indicate that use of the partial relations derived from the model (theory) can be very effective in prediction of either the results of machining with certain settings or calculation of the appropriate settings for achieving the required machining results. Therefore, these partial equations, which can be derived from the basic theoretical description and the respective model, can be used for preparation of control software with very high precision.

\section{Conclusions}

The presented theoretical model includes almost all parameters of either the plain water jet or the abrasive water jet, the machined material and other factors influencing the quantity and the quality of the workpiece. The resulting equations yield many oppor- 
tunities to use only the partial relations among few parameters or factors for a transfer of proven knowledge to the changed conditions. Some of these examples are presented and the difference between the respective theoretical and experimental values is below $5 \%$. Partial relations can be used in practice for preparation of control programs that can calculate very exact settings of changeable parameters from the proven results obtained with other settings or some "default settings".

Funding: Experiments presented in this paper were partially supported by projects SP 2017/44, SP 2018/43, SP2019/26, SP2020/45 and SP2021/64 funded by the Ministry of Education, Youth and Sports of the Czech Republic.

Institutional Review Board Statement: Not applicable.

Informed Consent Statement: Not applicable.

Data Availability Statement: Data sharing is not applicable to this article.

Conflicts of Interest: The author declares no conflict of interest.

\section{Nomenclature}

$\alpha$

$\alpha_{e}$

$\alpha_{n}$

$\gamma$

$\gamma_{o}, \gamma_{p}$

$\eta$

$\theta$

$\vartheta$

$\varphi$

$\chi$

$\mu, \mu_{o}$

$\rho, \rho_{o}$

$\rho_{a}$

$\rho_{j}$

$\rho_{m}$

$\rho_{M}$

$\rho_{M}^{*}$

$\sigma$

$\sigma_{m}$

$\sigma_{S}$

$\xi$

$\xi^{*}$

$\xi_{j}$

Coefficient of the velocity loss of the pure liquid jet in the interaction with material in a solid state (energetic coefficient) ... (-)

Experimentally determined coefficient of the abrasive water jet velocity loss in the interaction with material ... (-)

Coefficient of the velocity loss of the pure liquid jet in the interaction with material in a solid state after the $n$-th pass of the jet through the same trace ... (-)

Compressibility of the liquid for pressure $p_{0} \ldots\left(\mathrm{Pa}^{-1}\right)$

Shortened expression $\left(1-\gamma p_{0}\right) \ldots(-)$

Dynamic viscosity of the liquid ... ( $\left.\mathrm{N} \cdot \mathrm{s} \cdot \mathrm{m}^{-2}\right)$

Tilting angle of the cutting head measured in the plane containing the vector of the traverse speed and stating the deviation of the jet axis and the perpendicular in the point where the jet axis penetrates the inlet surface of material ... ( $\left.\operatorname{rad~or~}^{\circ}\right)$

Declination angle measured in the plane containing the vector of the traverse speed and stating the deviation of the tangent to the striation at the outlet surface of material and the inlet jet axis ... ( $\left.\operatorname{rad~or}^{\circ}\right)$

Inclination angle measured in the plane perpendicular to the plane containing the vector of the traverse speed and stating the deviation of the tangent to the side wall of the cut and the inlet jet axis ... ( $\left.\operatorname{rad~or}^{\circ}\right)$

Coefficient of the reflected liquid jet expansion due to the mixing with the disintegrated material (coefficient of the jet trace widening) ... (-)

Nozzle discharge coefficient... (-)

Density of the liquid under the normal conditions ... $\left(\mathrm{kg} \cdot \mathrm{m}^{-3}\right)$

Density of the abrasive material ... $\left(\mathrm{kg} \cdot \mathrm{m}^{-3}\right)$

Density of the abrasive jet (conversion to homogeneous liquid) ... $\left(\mathrm{kg} \cdot \mathrm{m}^{-3}\right)$

Density of material being machined ... $\left(\mathrm{kg} \cdot \mathrm{m}^{-3}\right)$

Specific volume density of disintegrated material (including pores) $\ldots\left(\mathrm{kg} \cdot \mathrm{m}^{-3}\right)$

Specific mass density of the disintegrated material (excluding pores) $\ldots\left(\mathrm{kg} \cdot \mathrm{m}^{-3}\right)$

Strength of the target material (compressive, tensile or shear) ... (Pa)

Strength of material being machined ... (Pa)

Shear strength of the target material ... (Pa)

Attenuation coefficient of the liquid jet between the nozzle outlet and the material surface ... $\left(\mathrm{m}^{-1}\right)$

Attenuation coefficient of the liquid jet in the already formed kerf ... $\left(\mathrm{m}^{-1}\right)$

Attenuation coefficient of abrasive jet in the environment between the focusing tube outlet and the material surface ... $\left(\mathrm{m}^{-1}\right)$

Mean size of the element of material structure-the grain ... (m)

Mean size of abrasive particles formed in the mixing process ... (m)

Mean size of particles (elements) of material—grains or their chips ... (m) 
Mean size of abrasive particles entering the mixing process ... (m)

Sound velocity inside the abrasive material $\ldots\left(\mathrm{m} \cdot \mathrm{s}^{-1}\right)$

Sound velocity inside the liquid used for preparation of the abrasive liquid jet (usually water) $\ldots\left(\mathrm{m} \cdot \mathrm{s}^{-1}\right)$

Friction coefficient of the liquid on the material element protruding to the jet flow ... (-) Coefficient modifying abrasive jet velocity in relation to the quantity of abrasive material input... (-)

Coefficient modifying abrasive jet velocity in relation to the ratio between the focusing tube diameter and the average abrasive particle size resulting from the mixing process ... (-)

Coefficient modifying abrasive jet velocity in relation to the friction inside the focusing tube... (-)

Coefficient modifying abrasive jet velocity in relation to the focusing tube opening ... (-)

Coefficient modifying abrasive water jet performance in relation to the changing content of abrasive below the so-called saturation level (above this level the jet performance increase is impossible and $\left.C_{A}=1\right) \ldots(-)$

Abrasive particle drag coefficient inside the liquid used for a preparation of the abrasive liquid jet (usually water) ... (-)

Water nozzle diameter (usually called orifice diameter) ... (m)

Focusing tube diameter... (m)

Resulting theoretical diameter of the outlet cylinder base of the sample cut by the abrasive water jet when the deformation caused by both the declination and the inclination angle is calculated ... (m)

Experimentally determined diameter of the cylindrical sample at the abrasive water jet inlet side ... (m)

Experimentally determined diameter of the cylindrical sample at the abrasive water jet outlet side ... (m)

Diameter of the cylindrical sample at the abrasive water jet inlet side calculated from the presented theoretical model ... (m)

Diameter of the cylindrical sample at the abrasive water jet outlet side calculated from the presented theoretical model ... (m)

Specific surface energy of the abrasive material ... (J)

Friction coefficient of abrasive particle on the focusing tube wall ... (-)

Depth of material disintegration (depth of cut) ... (m)

Maximum depth of liquid jet penetration into material for the selected conditions ... (m)

Depth of disintegration for the n-th pass of the jet through the same trajectory on the material surface ... (m)

Summary depth of the jet penetration into material after the $n$-th pass of the jet trace in the case of multiple passes through the same trajectory on the material surface ... (m)

Material thickness ... (m)

(Vickers') material hardness ... ( $\left.\mathrm{N} \cdot \mathrm{m}^{-2}\right)$

"Dynamic" permeability of material ... $\left(\mathrm{m}^{2}\right)$

Material hardness ... ( $\left.\mathrm{N} \cdot \mathrm{m}^{-2}\right)$

Length of the focusing tube ... (m)

Stand-off distance of the material surface or the investigated plane perpendicular to the liquid jet axis from the nozzle or the focusing tube outlet... (m)

Pressure of liquid before the nozzle (in the pump) ... (Pa)

Pressure obtained from Bernoulli's equation for a liquid with the density and the velocity of an abrasive jet... (Pa)

Abrasive mass flow rate $\ldots\left(\mathrm{kg} \cdot \mathrm{s}^{-1}\right)$

Water mass flow rate... $\left(\mathrm{kg} \cdot \mathrm{s}^{-1}\right)$

Radius of the pre-set circle path of the jet axis intersection with surface of material plate from which the sample is cut... (m)

Ratio between the quantity of non-damaged grains (i.e., not containing defects) and the total quantity of grains in the abrasive water jet ... (-)

Interaction time ... (s)

Correction of the outlet edge of the sample caused by the taper angle ... (m)

Abrasive jet speed after the mixing process ... $\left(\mathrm{m} \cdot \mathrm{s}^{-1}\right)$ 


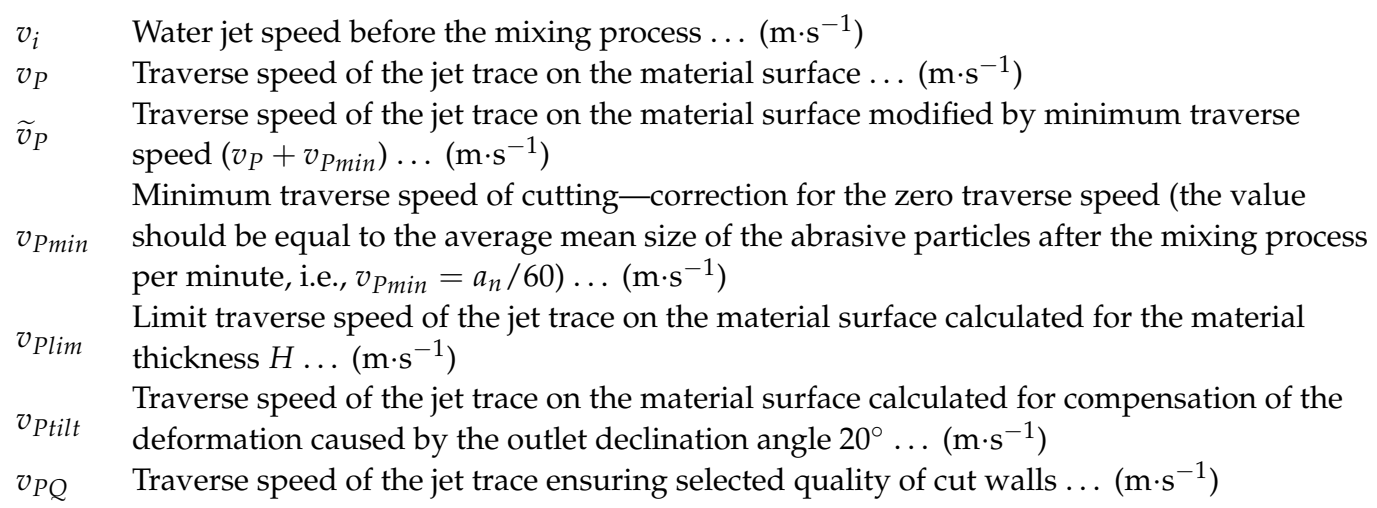

\section{References}

1. Crow, S.C. A Theory of Hydraulic Rock Cutting. Int. J. Rock Mech. Min. 1973, 10, 567-584. [CrossRef]

2. Rehbinder, G. A Theory about Cutting Rock with Water Jet. Rock Mech. 1980, 12, 247-257. [CrossRef]

3. Hashish, M. A modeling study of metal-cutting with abrasive waterjets. J. Eng. Mater. Technol. 1984, 106, 88-100. [CrossRef]

4. Hashish, M. A model for abrasive-Waterjet (AWJ) machining. J. Eng. Mater. Technol. 1989, 111, 154-162. [CrossRef]

5. Hlaváč, L. Physical description of high energy liquid jet interaction with material. In Proceedings of the International Conference Geomechanics, Hradec/Ostrava, Czechoslovakia, 24-26 September 1991; Rakowski, Z., Ed.; Balkema: Rotterdam, The Netherlands, 1992; pp. 341-346.

6. Zeng, J.; Kim, T.J. An erosion model of polycrystalline ceramics in abrasive waterjet cutting. Wear 1996, 193, 207-217. [CrossRef]

7. Kovacevic, R.; Yong, Z. Modelling of 3D abrasive waterjet machining: Part 1 -Theoretical basis. In Proceedings of the 13th International Conference on Jetting Technology, Cagliari, Sardinia, Italy, 29-31 October 1996; Gee, C., Ed.; Mechanical Engineering Publishing Ltd.: Bury St Edmunds, UK, 1996; pp. 73-82.

8. Yong, Z.; Kovacevic, R. Modelling of 3D abrasive waterjet machining: Part 2-Simulation of machining. In Proceedings of the 13th International Conference on Jetting Technology, Cagliari, Sardinia, Italy, 29-31 October 1996; Gee, C., Ed.; Mechanical Engineering Publishing Ltd.: Bury St Edmunds, UK, 1996; pp. 83-89.

9. Hlaváč, L.M. JETCUT-Software for prediction of high-Energy waterjet efficiency. In Proceedings of the 14th International Conference on Jetting Technology, Brugge, Belgium, 21-23 September 1998; Louis, H., Ed.; Professional Engineering Publishing Ltd.: London, UK, 1998; pp. 25-37.

10. Paul, S.; Hoogstrate, A.M.; van Luttervelt, C.A.; Kals, H.J.J. Analytical and Experimental Modeling of Abrasive Water Jet Cutting of Ductile Materials. J. Mater. Process. Technol. 1998, 73, 189-199. [CrossRef]

11. Paul, S.; Hoogstrate, A.M.; van Luttervelt, C.A.; Kals, H.J.J. Analytical Modeling of the Total Depth of Cut in Abrasive Water Jet Machining of Polycrystalline Brittle Materials. J. Mater. Process. Technol. 1998, 73, 206-212. [CrossRef]

12. Deam, R.T.; Lemma, E.; Ahmed, D.H. Modelling of the abrasive water jet cutting process. Wear 2004, 257, 877-891. [CrossRef]

13. Ma, C.; Deam, R.T. A correlation for predicting the kerf profile from abrasive water jet cutting. Exp. Therm. Fluid Sci. 2006, 30, 337-343. [CrossRef]

14. Hlaváč, L.M. Investigation of the abrasive water jet trajectory curvature inside the kerf. J. Mater. Process. Technol. 2009, 209, 4154-4161. [CrossRef]

15. Chen, F.L.; Wang, J.; Lemma, E.; Siores, E. Striation formation mechanisms on the jet cutting surface. J. Mater. Process. Technol. 2003, 141, 213-218. [CrossRef]

16. Orbanic, H.; Junkar, M. Analysis of striation formation mechanism in abrasive water jet cutting. Wear 2008, 265, 821-830. [CrossRef]

17. Zhang, S.J.; Wu, Y.Q.; Wang, S. An exploration of an abrasive water jet cutting front profile. Int. J. Adv. Manuf. Technol. 2015, 80, 1685-1688. [CrossRef]

18. Shanmugam, D.K.; Wang, J.; Liu, H. Minimisation of kerf tapers in abrasive waterjet machining of alumina ceramics using a compensation technique. Int. J. Mach. Tools Manuf. 2008, 48, 1527-1534. [CrossRef]

19. Hlaváč, L.M.; Hlaváčová, I.M.; Geryk, V.; Plančár, Š. Investigation of the taper of kerfs cut in steels by AWJ. Int. J. Adv. Manuf. Technol. 2015, 77, 1811-1818. [CrossRef]

20. Wu, Y.Q.; Zhang, S.J.; Wang, S.; Yang, F.L.; Tao, H. Method of obtaining accurate jet lag information in abrasive water-jet machining process. Int. J. Adv. Manuf. Technol. 2015, 76, 1827-1835. [CrossRef]

21. Srinivasu, D.S.; Axinte, D.A.; Shipway, P.H.; Folkes, J. Influence of kinematic operating parameters on kerf geometry in abrasive waterjet machining of silicon carbide ceramics. Int. J. Mach. Tools Manuf. 2009, 49, 1077-1088. [CrossRef]

22. Alberdi, A.; Rivero, A.; de Lacalle, L.N.L.; Etxeberria, I.; Suarez, A. Effect of process parameter on the kerf geometry in abrasive water jet milling. Int. J. Adv. Manuf. Technol. 2010, 51, 467-480. [CrossRef]

23. Hashish, M. Precision cutting of thick materials with AWJ. In Proceedings of the 17th International Conference on Water Jetting, Mainz, Germany, 7-9 September 2004; Gee, C., Ed.; BHR Group: Cranfield, UK, 2004; pp. 33-45.

24. Hashish, M. AWJ Milling of Gamma Titanium Aluminide. J. Manuf. Sci. Eng. 2010, 132, 041005. [CrossRef] 
25. Boud, F.; Carpenter, C.; Folkes, J.; Shipway, P.H. Abrasive water jet cutting of a titanium alloy: The influence of abrasive morphology and mechanical properties on workpiece grit embedment and cut quality. J. Mater. Process. Technol. 2010, 210, 2197-2205. [CrossRef]

26. Matsumura, T.; Muramatsu, T.; Fueki, S.; Hoshi, T. Abrasive water jet machining of glass with stagnation effect. CIRP Ann. 2011, 60, 355-358. [CrossRef]

27. Srinivas, S.; Babu, N.R. Penetration ability of abrasive waterjets in cutting of aluminum-silicon carbide particulate metal matrix composites. Mach. Sci. Technol. 2012, 16, 337-354. [CrossRef]

28. Akkurt, A. Cut Front Geometry Characterization in Cutting Applications of Brass with Abrasive Water Jet. J. Mater. Eng. Perform. 2010, 19, 599-606. [CrossRef]

29. Chen, M.; Zhang, S.; Zeng, J.; Chen, B.; Xue, J.; Ji, L. Correcting shape error on external corners caused by the jet cut-in/cut-out process in abrasive water jet cutting. Int. J. Adv. Manuf. Technol. 2019, 103, 849-859. [CrossRef]

30. Schwartzentruber, J.; Spelt, J.K.; Papini, M. Prediction of surface roughness in abrasive waterjet trimming of fiber reinforced polymer composites. Int. J. Mach. Tools Manuf. 2017, 122, 1-17. [CrossRef]

31. Pahuja, R.; Ramulu, M.; Hashish, M. Surface quality and kerf width prediction in abrasive water jet machining of metal-composite stacks. Compos. Part B Eng. 2019, 175, 107134. [CrossRef]

32. Anwar, S.; Axinte, D.A.; Becker, A.A. Finite element modelling of overlapping abrasive water jet milled footprints. Wear 2013, 303, 426-436. [CrossRef]

33. Wang, R.J.; Wang, C.Y.; Zheng, L.J.; Song, Y.X. Numerical simulation on the jet characteristics of abrasive jet. In Advances in Materials Manufacturing Science and Technology XV, Special Edition Materials Science Forum; Zhu, R., He, N., Fu, Y., Yang, C.Y., Eds.; Trans Tech Publications Ltd.: Zurich-Uetikon, Switzerland, 2014; Volume 770, pp. 257-262.

34. Wang, J.M.; Gao, N.; Gong, W.J. Abrasive waterjet machining simulation by SPH method. Int. J. Adv. Manuf. Technol. 2010, 50, 227-234.

35. Deepak, D.; Anjaiah, D.; Karanth, K.V.; Sharma, N.Y. CFD Simulation of Flow in an Abrasive Water Suspension Jet: The Effect of Inlet Operating Pressure and Volume Fraction on Skin Friction and Exit Kinetic Energy. Adv. Mech. Eng. 2012, 186430. [CrossRef]

36. Hlaváč, L.M.; Hlaváčová, I.M.; Jandačka, P.; Zegzulka, J.; Viliamsová, J.; Vašek, J.; Mádr, V. Comminution of material particles by water jets-influence of the inner shape of the mixing chamber. Int. J. Miner. Process. 2010, 95, 25-29. [CrossRef]

37. Hlaváčová, I.M.; Geryk, V. Abrasives for water-jet cutting of high-strength and thick hard materials. Int. J. Adv. Manuf. Technol. 2017, 90, 1217-1224. [CrossRef]

38. Aydin, G. Recycling of abrasives in abrasive water jet cutting with different types of granite. Arab. J. Geosci. 2014, 7, 4425-4435. [CrossRef]

39. Aydin, G. Performance of recycling abrasives in rock cutting by abrasive water jet. J. Cent. South. Univ. 2015, 22, 1055-1061. [CrossRef]

40. Jerman, M.; Orbanic, H.; Junkar, M.; Lebar, A. Thermal aspects of ice abrasive water jet technology. Adv. Mech. Eng. 2015, 1687814015597619. [CrossRef]

41. Borkowski, P.J. Application of abrasive-water jet technology for material sculpturing. Trans. Can. Soc. Mech. Eng. 2010, 34, 389-400. [CrossRef]

42. Schwartzentruber, J.; Papini, M. Abrasive water jet micro-piercing of borosilicate glass. J. Mater. Process. Technol. 2015, 219, 143-154. [CrossRef]

43. Haghbin, N.; Spelt, J.K.; Papini, M. Abrasive water jet micro-machining of channels in metals: Model to predict high aspect-ratio channel profiles for submerged and unsubmerged machining. J. Mater. Process. Technol. 2015, 222, 399-409. [CrossRef]

44. Babu, M.N.; Muthukrishnan, N. Investigation of multiple process parameters in abrasive water jet machining of tiles. J. Chin. Inst. Eng. 2015, 38, 692-700. [CrossRef]

45. Kvietkova, M.; Barcik, S.; Bomba, J.; Alac, P. Impact of chosen parameters on surface undulation during the cutting of agglomerated materials with an abrasive water jet. Drewno 2014, 57, 111-123.

46. Servátka, M.; Fabian, S. Experimental research and analysis of selected technological parameters on the roughness of steel area surface HARDOX 500 with thickness $40 \mathrm{~mm}$ cut by AWJ technology. Appl. Mech. Mater. 2013, 308, 13-18. [CrossRef]

47. Caydas, U.; Hascalik, A. A study on surface roughness in abrasive waterjet machining process using artificial neural networks and regression analysis method. J. Mater. Process. Technol. 2008, 202, 574-582. [CrossRef]

48. Singh, R.; Singh, V.; Gupta, T.V.K. An experimental study on surface roughness in slicing tungsten carbide with abrasive water jet machining. In Proceedings of the International Conference on Advances in Mechanical Engineering, ICAME 2020, Nagpur, India, 10-11 January 2020; Kalamkar, V.R., Monkova, K., Eds.; Springer: Singapore, 2021; pp. 353-359.

49. Jankovic, P.; Radovanovic, M.; Baralic, J.; Nedic, B. Prediction model of surface roughness in abrasive water jet cutting of aluminium alloy. J. Balk. Tribol. Assoc. 2013, 19, 585-595.

50. Hreha, P.; Radvanska, A.; Knapcikova, L.; Królczyk, G.M.; Legutko, S.; Królczyk, J.B.; Hloch, S.; Monka, P. Roughness parameters calculation by means of on-line vibration monitoring emerging from AWJ interaction with material. Metrol. Meas. Syst. 2015, 22, 315-326. [CrossRef]

51. Hlaváčová, I.M.; Mulicka, I. High-energy liquid jet technology—Risk assessment in practice. Int. J. Occup. Med. Env. 2012, 25, 365-374. [CrossRef] [PubMed] 
52. Fabian, S.; Salokyová, Š. AWJ cutting: The technological head vibrations with different abrasive mass flow rates. Appl. Mech. Mater. 2013, 308, 1-6. [CrossRef]

53. Narayanan, C.; Balz, R.; Weiss, D.A.; Heiniger, K.C. Modelling of abrasive particle energy in water jet machining. J. Mater. Process. Technol. 2013, 213, 2201-2210. [CrossRef]

54. Strnadel, B.; Hlaváč, L.M.; Gembalová, L. Effect of steel structure on the declination angle in AWJ cutting. Int. J. Mach. Tools Manuf. 2013, 64, 12-19. [CrossRef]

55. Hlaváč, L.M.; Strnadel, B.; Kaličinský, J.; Gembalová, L. The model of product distortion in AWJ cutting. Int. J. Adv. Manuf. Technol. 2012, 62, 157-166. [CrossRef]

56. Ahmed, D.H.; Naser, J.; Deam, R.T. Particles impact characteristics on cutting surface during the abrasive water jet machining: Numerical study. J. Mater. Process. Technol. 2016, 232, 116-130. [CrossRef]

57. Lari, M.R.S.; Papini, M. Inverse methods to gradient etch three-dimensional features with prescribed topographies using abrasive jet micro-machining: Part I-Modeling. Precis. Eng. 2016, 45, 272-284. [CrossRef]

58. Hlaváč, L.M. Application of water jet description on the de-scaling process. Int. J. Adv. Manuf. Technol. 2015, 80, 721-735. [CrossRef]

59. Hlaváč, L.M.; Hlaváčová, I.M.; Vašek, J.; Jandačka, P.; Zegzulka, J.; Viliamsová, J.; Mádr, V.; Uhlář, R. Investigation Of Samples From the High-Velocity Water Jet Driven Micro/Nano Particle Collider. Am. Soc. Mech. Eng. Press. Vessel. Pip. Div. 2010, 5, 119-126.

60. Galecki, G.; Sen, S.; Akar, G.; Li, Y.Q. Parametric Evaluation of Coal Comminution by Waterjets. Int. J. Coal Prep. Util. 2013, 33, 36-46. [CrossRef]

61. Hashish, M. Experimental studies of cutting with abrasive waterjets. In Proceedings of the 2nd U.S. Water Jet Conference, Rolla, Missouri, 24-26 May 1983; Summers, D.A., Haston, F.F., Eds.; WJTA: St. Louis, MO, USA, 1983; pp. 379-389.

62. Hlaváč, L.M.; Krajcarz, D.; Hlaváčová, I.M.; Spadło, S. Precision comparison of analytical and statistical-regression models for AWJ cutting. Precis. Eng. 2017, 50, 148-159. [CrossRef]

63. Hlaváč, L.M.; Hlaváčová, I.M.; Arleo, F.; Viganò, F.; Annoni, M.P.G.; Geryk, V. Shape distortion reduction method for abrasive water jet (AWJ) cutting. Precis. Eng. 2018, 53, 194-202. [CrossRef]

64. Hlaváč, L.M.; Hlaváčová, I.M.; Plančár, Š.; Krenický, T.; Geryk, V. Deformation of products cut on AWJ x-y tables and its suppression. In Proceedings of the International Conference on Mechanical Engineering and Applied Composite Materials, MEACM 2017, Hong Kong, China, 23-24 November 2017; IOP Conference Series: Materials Science and Engineering; IOP Publishing: Beijing, China, 2018; Volume 307, p. 0120152017.

65. Hlaváč, L.M.; Hlaváčová, I.M.; Vašek, J. Milling of materials by water jets—Acting of liquid jet in the cutting head. In TRANSACTIONS of the VSB - Technical University of Ostrava; Engineering Series; VSB-Technical University of Ostrava: Ostrava, Czech Republic, 2007; Volume LIII, pp. 73-84. 